\title{
Intelligence Analysis and Social Science Methods: Exploring the Potential for and Possible Limits of Mutual Learning
}

\author{
Mark Phythian
}

\begin{abstract}
This article considers the parallels between social science approaches to research and the practice of national security intelligence analysis. Just as it is important for policymakers and citizens to understand the limits to what intelligence can deliver, so it is important to recognize the limits to what social science methods can offer intelligence analysis. Moreover, it is at least equally important to recognise crucial differences in the environments in which mainstream social science research and national security intelligence analysis are conducted. A clear understanding of these is essential to thinking about the utility of social science approaches to intelligence analysis. Hence, the chapter begins by setting out what qualitative social science can offer and then goes on to explain why the straightforward application of social science techniques cannot of itself be regarded as a 'silver bullet' for the challenges confronting intelligence analysis.
\end{abstract}

\section{Introduction}

It makes good sense to suggest that social science approaches to research should form the methodological basis from which intelligence analysis proceeds, especially as the practice of intelligence analysis increasingly assumes the characteristics of a discrete profession. Indeed, the extent to which we can now speak of the profession of intelligence analysis owes much to the adoption and adaptation of social science techniques. ${ }^{1}$ However, just as it is important for

\footnotetext{
${ }^{1}$ There is some debate as to how far this is the case, although general agreement that this is the direction of travel. See, for example, Fisher, Johnston and Clement, 'Is Intelligence Analysis a Discipline?' They define a discipline as; "a type of profession, but one in which specialized knowledge and rigorous preparation are operationalized by the introduction of formal or informal governing bodies that are responsible for developing rules of a mandatory or voluntary nature that serve to guide, inform, and ensure the highest possible quality professional conduct and activity. Disciplines are professions that retain the collective wisdom of practitioners and establish standards for archiving and accessing that knowledge. Disciplines distinguish themselves by externally and internally derived licensing and credentialing practices, ethical standards, and continuing education requirements." See 57-8. See also the very useful discussion in Marrin, Improving Intelligence Analysis, Ch.8.
} 
policymakers and citizens to understand the limits of intelligence, so it is important in discussing what social science methods can offer intelligence analysis to recognise the limits of qualitative social science. Perhaps paradoxically such recognition may well foster a greater appreciation of what social science methods do offer. On this basis, this article begins by setting out what qualitative social science can offer. It goes on to explain why the straightforward application of social science techniques cannot of itself be regarded as a 'silver bullet' for solving the problems inherent in intelligence analysis, and finally suggests additional ways in which social science approaches or insights can yield benefits for intelligence organisations.

\section{Social Science and Intelligence Analysis: Applications and Limits}

At the outset, it is important to be clear about the nature and limitations of social science. It is also important to emphasise that I am focusing here on qualitative methods, which are those that approximate most closely to the job of the intelligence analyst. One reason why it is useful to be absolutely clear from the outset about what we mean by 'social science' arises from the inadequate understanding evident in some quarters when discussing social science contributions to intelligence analysis. One expression of this is a teleological view of social science methodology that sees its present state as one of underdevelopment, characterised by limited predictive capacity, but which will inevitably improve over time. ${ }^{2}$ This reflects a poor understanding of what social science can offer, in part a consequence of ill-founded comparisons with the natural sciences.

Properly understood, the rigorous application of social science methods can deliver much, but has clear limits that are unlikely to be affected except marginally by further methodological innovation or refinement. Qualitative social science's claim to 'scientific' status is based on its adherence to the following principles: ${ }^{3}$

1. Its objective is to generate inference, whether descriptive or explanatory, based on empirical information. This means that it is not simply about collecting facts. One of its defining characteristic is that, as scientific research, it goes 'beyond the facts' to draw conclusions - that is, inferences - from the collected data.

2. Its procedures are public. This means that it is explicit about its methods, thereby allowing others to make judgements about the validity of the findings from the methods

\footnotetext{
${ }^{2}$ For example, Ben-Israel, 'Philosophy and Methodology of Intelligence.'

3 The outline of the characteristics of social science research that follows is based on the definition provided in King, Keohane and Verba, Designing Social Inquiry,7-9.
} 
used, or test the findings by replicating the process. This means that social science research is a social enterprise; each research programme is no more than a contribution to a much broader effort being collectively undertaken by a community of researchers. The whole benefits from challenge and correction to its parts and this dynamic process is facilitated by its public nature.

3. Its conclusions are imperfect; social science recognises the impossibility of absolute certainty in conclusions. Inferences should therefore be accompanied by estimates of levels of certainty. As King, Keohane and Verba put it; "uncertainty is a central aspect of all research and all knowledge about the world."4

4. Scientific research depends on adhering to rules of inference. Hence, the 'scientific' component of social science research is not the subject matter, but the method, specifically the rigour with which the method is applied.

Social science research involves describing and explaining. Description must inevitably come first, but the relationship between description and explanation is an interactive one. It is important to recognise that description is a far from simple process. It involves selecting relevant or representative facts from a mass of data. Hence, it involves simplification. Crucially, it relies on detailed contextual understanding, otherwise the description on which the explanation rests, and hence the explanation, will be flawed and so misleading. Careful description forms a basis for explanation based on further organisation of facts, as observable implications of a theory or hypothesis.

Hence, social science research reduces a body of data into explanatory frames. A crucial question is; how much information is required to arrive at scientific conclusions? Given that conclusions are inevitably uncertain, there is no clear answer to this. Moreover, it is an area where the advent of 'big data' has posed a challenge to established social science approaches, ${ }^{5}$ although the idea that 'big data' can ever be complete and so omniscient, or that it can of itself provide an explanation for the trends it can illuminate, is highly problematic. It is a recognised principle of social science research that the more complex the event being studied, the less certain the inferences that can be drawn. However, reliability and quality of data are key elements of social science research. This means that while it is still possible to make inferences on the basis of limited data, these are likely to be highly uncertain, and for the process and

\footnotetext{
${ }^{4}$ Ibid, 9.

${ }^{5}$ For an overview, see Mayer-Schönberger and Cukier, Big Data.
} 
outcome to be regarded as scientific this fact and level of uncertainty would have to be acknowledged. In the absence of sufficient data on which to arrive at reasonably certain inferences, academic social science researchers (given that they are for the most part selftasking) are likely to shift their research focus to a topic that better rewards their efforts. Certainly, if a social science grant application was submitted to a funding body and conceded there was only very limited data available on which to base the project, it would be likely to be rejected. This is one of several linked areas where there is a clear tension between social science 'best practice' and the context in which national security intelligence analysis must be carried out.

\section{Incomplete Data}

For professional intelligence analysts, reflecting the reality of the data environment in which they have traditionally had to be prepared to work, limited data is enough. In fact, it is the norm. Indeed, the profession of intelligence analysis is itself a consequence of the reality of incomplete data; if data were bountiful then explanations of intentions and events would be relatively easy to discern. As Richards J. Heuer, Jr. put it:

A principal characteristic of intelligence analysis is that key information is often lacking. Analytical problems are selected on the basis of their importance and perceived needs of the consumers, without much regard for availability of information. Analysts have to do the best they can with what they have, somehow taking into account the fact that much relevant information is known to be missing. ${ }^{6}$

In illustrating these points, Heuer drew on social science experiments to show how more data does not necessarily result in better prediction. Taking an example from horseracing, he reported on how experienced handicappers were asked to rank variables that played a role in determining the outcome of races. Having ranked the variables by importance they were at first given just the top five sets of data, then 10, then 20 and finally all 40. In the experiment, these experienced handicappers did just as well with the more limited data as they did with a greater amount of data. In fact, some did worse with more data. Even so, their confidence in their ability to predict grew as they were provided with more data. ${ }^{7}$ This clearly suggests that simply having more data can produce diminishing returns. Note, however, that the limited information the handicappers began with was that which they regarded as the most important - a luxury

\footnotetext{
${ }^{6}$ Heuer Jr., Psychology of Intelligence Analysis, 119.

${ }^{7}$ Ibid, 51-55.
} 
that cannot be guaranteed outside the laboratory. At the same time, James Bruce has emphasised the fact that "in producing knowledge and foreknowledge, reliance on collected data makes analysis a fundamentally empirical enterprise”, and so conversely; "data-free intelligence is not intelligence. A major challenge of intelligence analysts, therefore, is not only to make judgments from the data but first to make judgments about the data." ${ }^{8}$

\section{A Retrospective Science}

A further tension between social science and intelligence analysis arises from a consideration of causality. When social scientists seek to explain the driving forces behind events - that is, provide causal explanations - they usually do so after the fact, when the outcome is known and when sufficient data is available. Causality is generally understood as explaining the relationship between one event (the cause) and a second, subsequent, event (the effect). As explained by David Hume in his A Treatise of Human Nature (1739):

1. The cause and effect must be contiguous in space and time.

2. The cause must be prior to the effect.

3. There must be a constant union betwixt the cause and effect. 'Tis chiefly this quality, that constitutes the relation. ${ }^{9}$

The key point here, then, is that causality is understood as the explanation of events that have already occurred.

While some social science theories claim to have predictive qualities, and some social scientists see prediction as being an important characteristic of a theory, ${ }^{10}$ in the field of political science, social science theories have a poor track record in predicting international developments. In short, prediction has been a problem. As historian John Lewis Gaddis has complained: "The trouble with the future is that it is much less knowable than the past." ${ }^{11}$ In a similar vein, another historian, Eric Hobsbawm, in his history of the 'short' twentieth century, Age of Extremes, reflected on a conundrum: "Why brilliant fashion-designers, a notoriously nonanalytic breed, sometimes succeed in anticipating the shape of things to come better than

\footnotetext{
${ }^{8}$ Bruce, 'Making Analysis More Reliable', 142. Emphasis in original. ${ }^{9}$ Source: http://oll.libertyfund.org/?option=com_staticxt\&staticfile=show.php\%3Ftitle=342\&chapter=55111\&layout=htm 1\&Itemid=27.

${ }^{10}$ Kegley, for example, has suggested that a theory must be able to do four things: describe, explain, predict, and prescribe. See, Kegley, Controversies in International Relations Theory, 8.

${ }^{11}$ Gaddis, The Landscape of History, 56.
} 
professional predictors." 12 This, Hobsbawm thought, "is one of the most obscure questions in history." 13 The solution to this particular conundrum seems rather straightforward; their interventions helped shape the "shape of things to come”. Still, all intelligence agencies (as far as we know) failed to predict the end of the Cold War, despite a pre-occupation with it. However, there was no shortage of social science explanation afterwards, when turning points could more easily be isolated and causality inferred from the evidence - the rise of Gorbachev; the Soviet withdrawal from regional conflicts, particularly Afghanistan; developments in arms control; the emancipation of Eastern Europe; and the reunification of Germany. ${ }^{14}$

A similar process can be found in the realm of the academic and/or professional study of economics. Here again, social science theories have demonstrated poor predictive capability, but provided frameworks that allow for post facto explanation of events which lead to improved understanding that can feed into future mitigating strategies. To take one example, in November 2008, the Queen opened a new building at the London School of Economics (LSE). She took the opportunity to ask the experts gathered around her why no one had predicted that year's global financial crisis. The Director of Research at the LSE's management department, Professor Luis Garicano, told reporters: "She was asking me if these things were so large how come everyone missed it.” ${ }^{15}$ This was a reasonable question and, having lost an estimated $£ 25$ million as a consequence of the financial crisis, the Queen had more than a passing interest in the answer. Unable to provide one on the spot, and feeling that they owed her an answer, leading academic and professional experts convened a forum in 2009 to arrive at one. They concluded that many did foresee the crisis, but that it was "the exact form that it would take and the timing of its onset and ferocity" which people failed to foresee. ${ }^{16}$ (There are echoes here of US intelligence responses to the accusation that it failed to anticipate the end of the Cold War.) With regard to the global financial crisis, analysts (risk managers) worked on compartmentalised issues and so failed to appreciate the risk to the system as a whole. In the context of the prosperity that came with unprecedented global expansion, and brought significant short-term gains for many, there was no incentive to confront the theoretical long-

\footnotetext{
12 Hobsbawm, Age of Extremes, 178.

13 Ibid.

${ }^{14}$ See, Herrmann and Lebow (eds.), Ending the Cold War.

${ }^{15}$ Pierce, 'The Queen asks why no one saw the credit crunch coming.'

${ }^{16}$ Besley \& Hennessy, letter to Her Majesty the Queen, 22 ${ }^{\text {nd }}$ July 2009, subsequently published as 'The Global Financial Crisis - Why Didn’t Anybody Notice?'
} 
term risk that this carried with it. Neither would politicians have been receptive to advice to do so:

All this exposed the difficulties of slowing the progression of such developments in the presence of a general 'feel-good' factor. Households benefited from low unemployment, cheap consumer goods and ready credit. Businesses benefited from lower borrowing costs. Bankers were earning bumper bonuses and expanding their business around the world. The government benefited from high tax revenues enabling them to increase public spending on schools and hospitals. This was bound to create a psychology of denial. It was a cycle fuelled, in significant measure, not by virtue but by delusion. ${ }^{17}$

This contains not so much a lesson for analysis per se, but more one of knowledge management (discussed further below) - for example, around the importance of undertaking strategic intelligence and avoiding the pathologies that can arise from organisational compartmentalisation. ${ }^{18}$ Nevertheless, this case shows how social science frameworks applied to studies of failure can raise awareness and point to where to look and the right questions to ask with a view to mitigating the risk of repetition. However, as this example also clearly demonstrates, social science is an inescapably retrospective science. This reality exposes the fact that the expectations surrounding social science and professional intelligence analysis are divergent; intelligence analysis will undoubtedly benefit from the application of social science techniques, but this should not obscure the reality that it constitutes a distinctive field which has adopted and adapted social science techniques to fit its own particular operating environment.

\section{Social Science and Creative Intuition}

This leads to a further point; while social science methodology recognises the importance of “creative intuition” in designing research questions and that inference has a creative element, creativity, imagination and speculative interpretation are much more central to intelligence analysis (as in "the art of" intelligence analysis) than to social science handling of data. In professional intelligence analysis, this can involve 'joining the dots' when not all dots are evident, with the attendant risk that dots that don't exist may be assumed to, leading to flawed analysis. ${ }^{19}$ Where limitations of data lead social scientists to seek other, more data-rich, options

\footnotetext{
17 Ibid, p.9.

${ }^{18}$ See, for example, Hislop, Knowledge Management in Organisations.

${ }^{19}$ See, Lowenthal, 'Towards a Reasonable Standard for Analysis.'
} 
intelligence analysts must find ways of addressing gaps, and creativity is an indispensable tool in doing so. However, too much creativity can be a problem. Given these differences, debates about the role, limits and potential pitfalls of creativity do not have the same prominence in social science research that they do in intelligence analysis. ${ }^{20}$

At the same time, it is important to recognise that grounding in social science is important to 'creative intuition' and that creative intuition is a result of a cognitive process. The Oxford English Dictionary defines 'intuit' as "to receive or assimilate knowledge by direct perception or comprehension”. It involves making links that connect facts and facilitate informal hypothesis testing in the context of incomplete information. It rests on informal mental guides. Clearly, this process is likely to be more useful if conducted by someone with expertise in the issue or region in question, and expertise in formal reasoning methodologies, than if conducted by someone with no previous exposure to these. Hence, 'creative intuition' in relation to intelligence analysis is linked to methodological, historical and subject expertise and is not an independently existing human gift.

We can explore this issue further via consideration of the example of the 9/11 terrorist attacks. This is a particularly appropriate case in that, in diagnosing a failure in this case to 'connect the dots', the 9/11 Commission called for, “a way of routinizing, even bureaucratizing, the exercise of imagination.”21 As far back as July 1995 a US National Intelligence Estimate had warned of the possibility of future terrorist attacks against the US, including within the US, and had warned that the danger of this happening would increase. It even, "specified as particular points of vulnerability the White House, the Capitol, symbols of capitalism such as Wall Street, critical infrastructure such as power grids, areas where people congregate such as sports arenas, and civil aviation generally." 22 However, intelligence failed from this point to ask the right questions about the gaps in its knowledge.

Should it have been possible to creatively intuit (or imagine) that terrorists would seek to fly passenger aircraft into high-profile buildings? In fact, the 9/11 Commission found that the possibility of the suicide hijacking of aircraft was "imaginable and imagined", although it was

\footnotetext{
${ }^{20}$ However, it is worth noting that the analysis offered to the Queen on the failure to predict the 2008 financial crisis, concluded, in what seems to be rather self-conscious imitation of the US 9/11 Commission, that it "was principally a failure of the collective imagination of many bright people, both in this country and internationally, to understand the risks to the system as a whole.” Besley \& Hennessy, 'The Global Financial Crisis - Why Didn’t Anybody Notice?', 9.

${ }^{21}$ 9/11 Commission, Final Report, 344.

22 Ibid, 341.
} 
not adopted as a hypothesis to be pursued. ${ }^{23}$ What would such creative intuition have been based upon? Analysts did have the precedent of the Christmas Eve 1994 hijacking of Air France flight 8969 at Houari Boumedienne Airport in Algiers to work from. From here the Algerian Armed Islamic Group (GIA) hijackers had intended to either explode the aircraft over Paris or fly it into the Eiffel Tower. At the same time, in academic journals, terrorism experts had begun to warn about the confluence of religious terrorism and the 'amateurisation' of terrorism and its implications. ${ }^{24}$ Moreover, and perhaps more famously, the 1994 Tom Clancy novel, Debt of Honor, featured a Boeing 747 passenger aircraft being flown into the capitol building. This is not at all to suggest that analysts should have been expected to piece together such fragments and through doing so anticipate the 9/11 attacks. We clearly need to bear in mind Roberta Wohlstetter's observation in relation to her study of the failure to anticipate the Japanese attack on Pearl Harbor, that: “After the event... a signal is always crystal clear; we can now see what disaster it was signalling since the disaster has occurred. But before the event it is obscure and pregnant with conflicting meanings." ${ }^{25}$ Moreover, as the 9/11 Commission Report noted, a key issue was how to attach due weight to such creative thinking within the analytic process and how to understand just what constituted 'due weight' in this case. For example, although counter-terrorism czar Richard Clarke had been concerned about the risk that aircraft might pose as weapons since the time of the 1996 Atlanta Olympics even he felt that with regard to the potential al-Qaeda threat, "warning about the possibility of a suicide hijacking would have been just one more speculative theory among many”, which numbered somewhere between the tens and hundreds of thousands. ${ }^{26}$

There are two interlinked issues here. The first is the place of creativity in filling the inevitable gaps in understandings of an inherently uncertain threat environment. The second concerns how this should be best captured and incorporated by the organisational context within which analysis is undertaken. My essential point here, though, is to highlight how the kind of creative intuition that led in this direction would have been rooted in and have sprung from expertise and a process of mental mapping that involved a form of hypothesis construction and drew on critical thinking skills associated with social science. Just like more formal hypothesis testing

\footnotetext{
${ }^{23}$ Ibid, 345. Marrin discusses this in terms of strategic intelligence failure in his 'The 9/11 Terrorist Attacks.'

${ }^{24}$ Hoffman, 'Intelligence and Terrorism.' Having said this, experts in academia also failed to anticipate 9/11 those working in the fields of international relations and international security tending, like the Bush Administration prior to 9/11, to focus on the potential threat posed by the rise of China. See, for example, Czwarno, 'Misjudging Islamic Terrorism.'

${ }^{25}$ Wohlstetter, Pearl Harbor, 387.

${ }^{26}$ In the words of the 9/11 Commission Report, 345.
} 
it would have been based on mental models of individual and group motivation and behaviour that are themselves based on social science theories, however implicitly. It is worth noting here as well that analysts are not always explicit about the theories and models on which their analysis is based. For example, one of the most striking things about the intelligence literature written by current and former intelligence professionals in the West is the frequency with which it adopts a structural realist understanding of the world, without ever explicitly recognising this.

\section{Temporality and Intelligence Analysis: The Key Distinction}

Another key factor distinguishing social science best practice from intelligence analysis is one that is actually present in each of the areas discussed above. There are a range of definitions of intelligence, many of which incorporate the notion of timeliness in one form or another. For example, Peter Gill and myself have defined intelligence as; "the umbrella term referring to the range of activities - from planning and information collection to analysis and dissemination - conducted in secret, and aimed at maintaining or enhancing relative security by providing forewarning of threats or potential threats in a manner that allows for the timely implementation of a preventive policy or strategy, including, where deemed desirable, covert activities.”27 However, some definitions go beyond mere timeliness. For example, James Bruce has defined intelligence as "knowledge and foreknowledge of the world around us that allows civilian leaders and military commanders to consider alternative options and outcomes in making decisions." 28 If the role of intelligence analysts is to produce knowledge and foreknowledge (the latter defined in the Oxford English Dictionary as, "knowledge of an event, etc. before it exists or happens”), then this clearly takes us beyond core social science epistemology. Indeed, James' use of foreknowledge is interesting in epistemological terms; it represents a qualitative leap from the notion that intelligence is about forewarning - i.e. identifying a potential risk from within uncertainty. ${ }^{29}$ Bruce seems to be talking about knowledge of something that has yet to happen. In a sense, the appropriate framework for dealing with this is not social science but science fiction; it is the realm of Philip K. Dick and precognition. ${ }^{30}$ Having said that, it is also an area where 'big data' has intervened with regard to, for example, predictive policing models pushed by the private sector, holding out the promise of the predictive capability that

\footnotetext{
${ }^{27}$ Gill and Phythian, Intelligence in an Insecure World,19.

${ }^{28}$ Bruce, 'Making Analysis More Reliable', 171.

${ }^{29}$ On this, see Phythian, 'Policing Uncertainty.'

${ }^{30}$ Dick, 'The Minority Report.'.
} 
social science cannot deliver. ${ }^{31}$ This is an area where professional intelligence analysis and social science are likely to diverge; social science interrogating the claims made on behalf of 'big data' and intelligence buying into the promise of prediction.

This imperative to capture something that is beyond the reach of conventional social science methodologies means that intelligence operates in what we can term a 'post-normal' context. ${ }^{32}$ The concept of 'post-normalcy' is rooted in an understanding of how science should proceed in 'normal' circumstances. Here, in the context of what have been termed low systems uncertainties and low decision stakes, a traditional applied science approach applies. In such contexts, uncertainties will be limited to the technical level and so will be adequately managed by standard routines and procedures. At the same time, the decision stakes are also limited, which means that the external operating environment does not function as a source of pressure that impacts on the environment in which the research is conducted. Instead, as Funtowicz and Ravetz explain, "resources have been put into the research exercise because there is some particular straightforward external function for the results. The resulting information will be used in a larger enterprise, which is of no concern to the researcher on the job.”33

By contrast, in 'post-normal' science systems uncertainties and decision stakes are both high. Here science operates in conditions of significant uncertainty in which policy-makers create pressure by demanding results on issues where there is a perceived need for political action. Time is a key factor here. It is also a factor in social science research, of course, but not in the manner or the extent it is with regard to post-normal intelligence analysis. The application, and even repeated application, of social science methodologies requires time. Moreover, there are not inconsiderable time implications in arriving at the point where these can be applied. As King et al emphasise:

Where possible, analysts should simplify their descriptions only after they attain an understanding of the richness of history and culture. Social scientists may use only a few parts of the history of some set of events in making inferences. Nevertheless, rich, unstructured knowledge of the historical and cultural context of the phenomena with

\footnotetext{
${ }^{31}$ See, for example, The Economist, 'Predictive Policing'; Goode, 'Sending the Police Before There's a Crime.' See also Mayer-Schönberger and Cukier, Big Data, Ch.8.

32 Phythian, 'Policing Uncertainty'. In this I am applying the approach of Funtowicz and Ravetz to the realm of national security intelligence practice.

${ }^{33}$ Funtowicz and Ravetz, 'Science for the Post-Normal Age.'
} 
which they want to deal in a simplified and scientific way is usually a requisite for avoiding simplifications that are simply wrong. ${ }^{34}$

Similarly, with regard to the importance attached to creative intuition in intelligence analysis having the 'space' (i.e. time) in which to be creative is clearly important. This also takes us to the heart of the debate around strategic versus current intelligence. There is clearly a risk that demands for current intelligence can adversely affect the ability of analysts to meet the requirements of effective description, the prerequisite for effective explanation in social science methodologies.

There are, then, clear parallels between post-normal science conditions and the national security intelligence analytic environment, a consequence of its need to make 'up-stream' interventions, often in a time-constrained context, in order to attempt to attain foreknowledge, in Bruce's terms. Time constraints, it would seem, foreclose the possibility of replicating the repeated testing that social science methodology requires. For example, the intelligence environment in both the US and UK in the months leading to the 2003 war with Iraq was 'postnormal', compromising standard procedures in both cases. Best practice in social science methodology tells us that rigour in the construction and testing of causal hypotheses and theories are essential foundations of scientific research. However, one of the remarkable characteristics of the Iraq failure in the US and UK is the absence of any alternative hypotheses to the assumption that Iraq had, but had effectively concealed, WMD. Not only were no alternative hypotheses tested, information that could have pointed to alternative hypotheses was either ignored or suppressed, while weak information that supported the hypothesis was given prominence.

This is a core criticism that emerges from the lengthy UK inquiry into the Iraq War chaired by Sir John Chilcot, which finally reported in the summer of 2016. Its Report emphasised that: “The core construct that Saddam Hussein's regime retained chemical and biological warfare capabilities, was determined to preserve and if possible enhance its capabilities, including at some point in the future a nuclear capability, and was pursuing an active policy of deception and concealment, underpinned the UK Government position that Iraq was a threat that had to be dealt with and it needed to disarm or be disarmed." 35 Chilcot also found that judgements about Iraq's capabilities and intentions relied heavily on Iraq's past behaviour being a reliable

\footnotetext{
${ }^{34}$ King et al, Designing Social Inquiry, 43.

${ }^{35}$ Chilcot, The Report of the Iraq Inquiry, Section 4.3, para. 664.
} 
indicator of its current and future actions. In the post-September 2002 period, following the call for intelligence to feed into and publication of a dossier designed to make the case for war, there was no consideration of whether, faced with the prospect of a US

Hussein had taken a different position. The absence of evidence of proscribed programmes and materials relating to the production or delivery of chemical, biological or nuclear weapons was, Chilcot found, “attributed to Iraq's ability to conceal its activities and deceive the inspectors and the difficulties which it had been anticipated the inspectors would encounter." ${ }^{36}$ In a similar vein, Iraq's statements that it had no weapons or programmes were dismissed as further evidence of a strategy of denial.

The Chilcot Report cites John Scarlett, Chair of the UK's Joint Intelligence Committee at the time, writing on $30^{\text {th }}$ January 2003 that it was odd that the Iraqi regime did not appear "to be worried about the obvious risk of leaks from the thousands of people aware of this concealment activity”. ${ }^{37}$ This line of thinking, involving as it did consideration of the uniformly high levels of discipline that would have needed to have been maintained if this were indeed the case, should have set off alarm bells, prompting consideration of alternative hypotheses. Instead, Scarlett attributed the regime’s success in avoiding leaks to its "brutal discipline”, at the same time admitting that he continued: “... to be struck by the regime's ability to conduct complex surveillance and deception operations without unforced errors or major slip ups. Co-ordinating the dispersal of materials and associated documentation around the country and fielding surprise UNMOVIC and IAEA visits to hundreds of sites in a few weeks is a complex undertaking and evidence of the regime's continuing grip on the population at least of central Iraq."38

Asked whether the intelligence on Saddam Hussein's strategy for dealing with inspections reinforced the view that there really was something to hide, an SIS witness told the Inquiry: "I think they looked guilty as hell. In a way it's a sort of spectacular miscalculation, and I think it's partly because of their paranoia about being open to hostile scrutiny, and partly because they had stuff to hide, but not necessarily what the inspectors were looking for...So there was quite a lot of evidence of the unco-operative and mule-headed and crude efforts to make the inspectors' life more difficult...Yes, and it seemed to form part of a consistent picture,

\footnotetext{
${ }^{36}$ Ibid, para. 674.

${ }^{37}$ Ibid, para. 677.

${ }^{38}$ Ibid, para. 678.
} 
allowing for the fact that there was a certain assumption in the first place about what that picture was." 39

However, as the Chilcot Report notes, there were other possible reasons "why an insecure regime, convinced that past inspections had been used for espionage and facing military attack, would want to limit the conversations key personnel were having with foreigners while military action was threatened." 40 As the post-war US Iraq Survey Group concluded from its interviews with Iraqi former officials, Iraq's concealment strategy was, in significant part, intended to conceal its strategic weakness from Iran. As Chilcot demonstrates, this did not emerge as a hypothesis to be tested during the entire period from September 2002 to the war in March 2003.

Hence, the tendency towards intuitive short-cuts, of the sort seemingly made by John Scarlett in the example above, as an alternative to formal hypothesis testing arises from this post-normal reality. A rigid formal application of positivist methods in arriving at every judgement is unrealistic in the post-normal context in which intelligence operates. Indeed, as suggested earlier, there is a case for regarding hypothesis testing and reliance on creative intuition not as constituting separate, completely unrelated, approaches to analysis and instead to see them as points on a continuum where the frequency of their use is determined by external and organisational context as much as anything else. On this basis, then, any assumption that intelligence analysis can simply mirror social scientific best practice is misplaced, because it fails to recognise the crucial fact that intelligence analysis operates in a different and more complex, post-normal, environment.

How should intelligence organisations respond to the reality of post-normalcy in order to promote optimal performance? The first step is to recognise that contexts can be post-normal, and to understand the challenges that this implies. The second is to codify the place of inputs based on creative intuition, in recognition of post-normalcy. As argued above, creative intuition is, after all, likely to have a social science basis. If the environment determines that this is how analysis must be performed at least some of the time, then organisations have a vested interest in fully exploring what it means and how its effectiveness can be optimised. Nevertheless, a vital third step is to continue to emphasise the importance of causal theory construction and testing in the process of intelligence analysis wherever the context makes this feasible. In this, follow social science best practice. For example, causal theories should be designed so as to be

\footnotetext{
${ }^{39}$ Ibid, para. 693. My emphasis.

${ }^{40}$ Ibid, para. 692.
} 
falsifiable. It is important to remember that advances in understanding arise from disproving causal hypotheses just as much as they do from proving them. Most useful social science theories only hold good in specific circumstances (e.g. in relation to certain forms of government, or in certain types of election), and in recognition of this the bounds of applicability of a theory or hypothesis should be indicated. What is it that dictates these bounds? More significantly still, always pose the question: what evidence would falsify this theory? Then, does such evidence exist? ${ }^{41}$ Rigorous testing is key. As Kellstedt and Whitten advise:

A core part of the scientific process is scepticism. On hearing of a new theory, other scientists will challenge this theory and devise further tests. Although this process can occasionally become quite combative, it is a necessary component in the development of scientific knowledge. Indeed, a core component of scientific knowledge is that, as confident as we are in a particular theory, we remain open to the possibility that there is still a test out there that will provide evidence that makes us lose confidence in that theory. ${ }^{42}$

In intelligence analysis this means institutionalising a way of doing this that is immune to political pressure, in order to compensate for the absence of the core characteristics of open social scientific research that I outlined earlier, via forms of competitive analysis. It means taking seriously the Analysis of Competing Hypotheses (ACH) model, ${ }^{43}$ but also broadening the range of those involved in testing hypotheses and theories so as to replicate the 'public' dimension of social science research, resulting in less of a feeling that analysis is being refined in a silo. The US intelligence community has made serial efforts to overcome the barrier of the 'public dimension', but it still represents a fundamental challenge for all closed organisations. ${ }^{44}$

\section{Intention, Denial \& Deception}

There is a further tension arising from fundamental differences between social science research and the nature of intelligence analysis. It is a rule of thumb in social science theory that in constructing a hypothesis one should select observable concepts as far as possible in order to "maximise concreteness." 45 Standard advice is to steer clear of abstract concepts such as

\footnotetext{
${ }^{41}$ See the discussion in King et al, Designing Social Theory, 100-05.

${ }^{42}$ Kellstedt and Whitten, The Fundamentals of Political Science Research, 4.

${ }^{43}$ Heuer, Psychology of Intelligence Analysis, 97.

${ }^{44}$ See the discussion in Marrin, Improving Intelligence Analysis, Ch.3.

${ }^{45}$ King et al, 109-10.
} 
intention, motivation and identification. But these are precisely the key issues that intelligence analysts need to address, the ones that technical collection methods are less likely to be able to explain. Hence, there has been some scepticism about the utility of causal inference to intelligence analysis. In the Psychology of Intelligence Analysis, Heuer offered examples which he considered; "suggest that in military and foreign affairs, where the patterns are at best difficult to fathom, there may be many events for which there are no valid causal explanations." 46

A final post-normal characteristic relates to the question of denial and deception. Social scientists will weigh the reliability of evidence and will be alert to the limits of different types of evidence (and vested interests of different kinds of interview subject), but do not have to operate on the principle that evidence may have been constructed with the deliberate and principal aim of misleading them. In the case of intelligence analysis, however, Heuer suggests that if you hypothesise that an opponent is attempting to deceive you:

You may reject the possibility of denial and deception because you see no evidence of it, but rejection is not justified under these circumstances. If deception is planned well and properly implemented one should not expect to find evidence of it readily to hand. The possibility should not be rejected until it is disproven, or, at least, until after a systematic search for evidence has been made and none has been found. ${ }^{47}$

But what would constitute acceptable evidence in this context? Are there reliable indicators as to when to recognise that the absence of evidence reflects an erroneous hypothesis rather than the successful application of sophisticated denial and deception techniques? This question, of course, returns us to the territory examined in the Chilcot Report. In this wilderness of mirrors, the 'rules' of social science research are inadequate guarantees against being deceived - or, if pursued to their logical conclusion, will do nothing but immobilise the analyst in a sea of uncertainty. Causal explanation is unlikely to capture everything, but to go back to my starting point about the promise and limits of social science, these are claims that social science research does not make for itself; conclusions are uncertain because inference is an imperfect process. Similarly, over 50 years ago the historian E. H. Carr made the point that causality could only capture what he termed the rational causes of an event, but not what he termed the

\footnotetext{
${ }^{46}$ Heuer, 131.

47 Ibid, 98.
} 
'accidental'. ${ }^{48}$ Social scientists attempt to allow for such developments by distinguishing between systematic and non-systematic differences affecting outcomes, but the complexity of the political world means that inferences drawn here are inevitably strongest in relation to the period during which the research was undertaken.

To return to an earlier point, given all of this, perhaps social science methods might be most useful in post-mortem analyses of intelligence failure, ${ }^{49}$ employing case study approaches that test causal hypotheses. In this context, Andrew Hindmoor and Allan McConnell have proposed one framework via which backward mapping (as opposed to forward mapping) could be applied across a wide range of cases. ${ }^{50}$ One additional useful method would be to draw on counterfactuals. ${ }^{51}$ Commissioning groups of outside experts to produce parallel analyses and then comparing the results would be useful in illuminating particular cases, or groups of cases, and also aiding reflection on analytic practice more generally.

\section{Further Explorations of Social Science}

Thus far this discussion has focussed on the approach to social science that intelligence analysts and organisations have most commonly drawn on, and the tensions that exist between social science and intelligence requirements and contexts. This has focused on positivist social science. It is understandable that intelligence organisations and individual analysts should be sceptical about post-positivist approaches that question the existence of a single 'truth'. Nevertheless, intelligence organisations and analysts could benefit from a deeper exploration of the potential of some post-positivist approaches. For example, earlier I noted Eric Hobsbawm's incomprehension in the face of fashion designers' ability to predict trends in fashion, an ability that could be explained, at least in part, by reference to the impact of their own interventions in the operating environment. However, this same reflexive capacity or risk exists with regard to intelligence - its interventions, even via the process of observation, can impact on and so alter the external environment. Analysts clearly need to be alert to this risk, one that is most clearly explained by social science frameworks. ${ }^{52}$ Equally, social science approaches to risk and uncertainty can improve individual and organisational understanding.

\footnotetext{
${ }^{48}$ Carr, What is History? Ch.4.

${ }^{49}$ I note the post-mortem dimension of academic Intelligence Studies in Phythian, 'Intelligence Theory and Theories of Intelligence.' See, 62-3. See also, Wirtz, 'The Art of the Intelligence Autopsy.’ Note that Wirtz’s title refers to the art rather than the science of the autopsy.

${ }^{50}$ Hindmoor and McConnell, 'Why Didn’t They See It Coming?'

${ }^{51}$ On this, see Lebow, Forbidden Fruit.

52 See, for example, Fry and Hochstein, 'Epistemic Communities’; Phythian, 'Policing Uncertainty’; Warner, 'Intelligence and Reflexivity.' See also the discussion in Warner, 'Theories of Intelligence.'
} 
Given that some of the more insightful accounts of the intelligence failures of the $21^{\text {st }}$ century focus on structural explanations, ${ }^{53}$ there is potential for intelligence organisations to benefit from emerging areas of social science, such as knowledge management, that focus on the organisation. The premise here is that the effective management of knowledge within an organisation is likely to result in competitive advantage. ${ }^{54}$ As a developing social science field, knowledge management has addressed key issues that face intelligence organisations - for example, the relationship between time and knowledge ('temporal convergence') ${ }^{55}$ - and modelled knowledge-based strategy-making processes, the latter of these having the capacity to inform thinking about the intelligence process. ${ }^{56}$ Aside from this, critical thinking rooted in social science methodologies has led directly to proposals for different ways of conceptualising the intelligence process or 'cycle'. ${ }^{57}$ Hence, beyond the application of positivist methods, social science has much to offer intelligence analysts and organisations in providing a basis for critical reflection on organisational structures, procedures and management of knowledge. The distinct impression, however, is that to date they have been under-utilised.

\section{Conclusions}

Intelligence analysis takes place in a different, post-normal, context to best practice social science research, generating specific challenges. There are additional contrasts that arise from this fundamental difference; for example, in that causal explanation is required to facilitate prediction as much as explanation with regard to intelligence analysis. Hence, while the need for each arises from the same fundamental issue - that facts do not speak for themselves and need to be organised and analysed to give them meaning - they represent discrete fields. One adapts and adopts elements of the other, but is nevertheless a distinctive pursuit.

Creative intuition, while a factor in hypothesis construction in the social sciences, is recognised as having a much more important role to play in intelligence analysis. It should not be assumed, though, that this process is without roots in social science methods of inquiry. Creative intuition as informal hypothesis-testing in response to the demands of post-normalcy is a fact of intelligence life, and should be recognised as such. Having said this, intelligence analysis needs to continue to be grounded in a solid analytical method that accords a high priority to hypothesis

\footnotetext{
${ }^{53}$ For example, Zegart, Spying Blind.

${ }^{54}$ Hislop, Knowledge Management in Organizations, 2.

${ }^{55}$ Martin, Philp and Hall, 'Temporal Convergence for Knowledge Management.'

${ }_{56}$ Massingham, 'Linking Business Level Strategy with Activities and Knowledge Resources.'

${ }^{57}$ For example, Phythian (ed.), Understanding the Intelligence Cycle.
} 
and theory construction and testing wherever feasible, and to continue to search for ways of replicating the social dimension of social science in this testing. Absent this, intelligence analysts risk being little different from government lawyers, given that it is their different approaches to evidence that separate these professions. As Kellstedt and Whitten put it:

Lawyers work for a particular client, advocate a particular point of view (like "guilt" or “innocence”), and then accumulate evidence with a goal of proving their case to a judge or jury. This goal of proving a desired result determines their approach to evidence. When faced with evidence that conflicts with their case, lawyers attempt to ignore or discredit such evidence. When faced with evidence that supports their case, lawyers try to emphasize the applicability of the supportive evidence. In many ways, the scientific and legal approaches to evidence couldn't be further apart. Scientific confidence in a theory is achieved only after hypotheses derived from the theory have run a gauntlet of tough tests. At the beginning of a trial, lawyers develop a strategy to prove their case. In contrast, at the beginning of a research project, scientists will think long and hard about the most rigorous tests that they can conduct. ${ }^{58}$

It is almost certainly the case that a number of national intelligence agencies could improve their analytical product by more closely following best practice in qualitative social science research methods. It is also the case that there is a social science world beyond positivism that could yield important insights and improvements at the levels of the analyst and the organisation. However, there is also a need for a word of caution based on recent intelligence history. The principal reasons for the Iraq failure are not to be found in a failure to recognise what constituted 'best practice', but in a failure to apply it. Hence, the most pressing issues would seem to be as much structural as narrowly analytical; as much about knowledge management as simply about knowledge. The key question for analysts and managers alike is; how can intelligence analysis continue to meet the (high) expectations that surround it in postnormal conditions? Recognising and accommodating the demands of post-normalcy in the analytic process in the most efficacious manner possible becomes the key task.

Author's Note: I would like to thank Stephen Marrin for his helpful comments on an earlier draft of this chapter.

\footnotetext{
${ }^{58}$ Kellstedt \& Whitten, The Fundamentals of Political Science Research, 4.
} 
Contact Mark Phythian Email mp249@le.ac.uk

\section{Notes on Contributor}

Mark Phythian is Professor of Politics in the School of History, Politics and International Relations at the University of Leicester, UK. He is the author or editor/co-editor of a number of books, including: Intelligence Theory: Key Questions and Debates (edited with Peter Gill \& Stephen Marrin, Routledge, 2008); Intelligence in an Insecure World (with Peter Gill, 2nd ed. Polity Press, 2012); and Understanding the Intelligence Cycle (Routledge, 2013), as well as numerous journal articles and book chapters. He is co-editor of the leading intelligence journal, Intelligence and National Security, a member of the editorial boards of the International Journal of Intelligence, Security and Public Affairs and the Journal of Intelligence History, an Associate Editor of Crime, Law and Social Change, and a Fellow of the UK Academy of Social Sciences.

\section{References}

9/11 Commission: Final Report of the National Commission on Terrorist Attacks Upon the United States. New York: W. W. Norton \& Co. 2004.

Ben-Israel, Isaac. "Philosophy and Methodology of Intelligence: The Logic of Estimate Process.” Intelligence and National Security 4, no. 4 (1989): 660-718.

Besley, Tim, and Peter Hennessy, “The Global Financial Crisis - Why Didn’t Anybody Notice?” British Academy Review 14 (November 2009): 8-10:

http://www.britac.ac.uk/pubs/review/14/.

Bruce, James B., “Making Analysis More Reliable: Why Epistemology Matters to Intelligence.” In Roger Z. George and James B. Bruce (eds.), Analyzing Intelligence: National Security Practitioners’ Perspectives. Washington, DC: Georgetown University Press, 2014:135-55.

Carr, E. H. What is History? London: Macmillan, 1961.

Chilcot, Sir John. The Report of the Iraq Inquiry. London: HMSO, July 2016: www.iraqinquiry.org.uk/the-report/ 
Czwarno, Monica. “Misjudging Islamic Terrorism: The Academic Community’s Failure to Predict 9/11.” Studies in Conflict and Terrorism 29, no. 7 (2006): 657-78.

Dick, Philip K. “The Minority Report.” In Philip K. Dick, Minority Report: Volume Four of the Collected Stories. London: Gollancz, 2000: 71-102.

The Economist. "Predictive Policing: Don’t Even Think About It.” 20 July 2013: http://www.economist.com/news/briefing/21582042-it-getting-easier-foresee-wrongdoingand-spot-likely-wrongdoers-dont-even-think-about-it.

Fisher, Rebecca, Rob Johnston and Peter Clement. “Is Intelligence Analysis a Discipline?” In Roger Z. George and James B. Bruce (eds.), Analyzing Intelligence: National Security Practitioners’ Perspectives. Washington, DC: Georgetown University Press, 2014: 57-77. Fry, Michael G. and Miles Hochstein. "Epistemic Communities: Intelligence Studies and International Relations.” Intelligence and National Security 8, no. 3 (1993): 14-28.

Funtowicz, Silvio O. and Jerome R. Ravetz. “Science for the Post-Normal Age.” Futures 25, no. 7 (1993): 739-55.

Gaddis, John Lewis. The Landscape of History: How Historians Map the Past. New York: Oxford University Press, 2002.

Gill, Peter and Mark Phythian. Intelligence in an Insecure World. $2^{\text {nd }}$ edition. Cambridge: Polity Press, 2012.

Goode, Erica. “Sending the Police Before There’s a Crime.” New York Times, 15 August 2011.

Herrmann, Richard K. and Richard Ned Lebow (eds.). Ending the Cold War: Interpretations, Causation, and the Study of International Relations. New York: Palgrave Macmillan, 2004.

Heuer Jr., Richards J. Psychology of Intelligence Analysis. Washington, DC: Center for the Study of Intelligence, 1999.

Hindmoor, Andrew and Allan McConnell. “Why Didn’t They See It Coming? Warning Signs, Acceptable Risks and the Global Financial Crisis.” Political Studies 61, no. 3 (2013): 543-60. 
Hislop, Donald. Knowledge Management in Organisations: A Critical Introduction. $3^{\text {rd }}$ edition. Oxford: Oxford University Press, 2013.

Hobsbawm, Eric. Age of Extremes: The Short Twentieth Century 1914-1991. London: Michael Joseph/Penguin, 1994.

Hoffman, Bruce. "Intelligence and Terrorism: Emerging Threats and New Security Challenges in the Post-Cold War Era.” Intelligence and National Security 11, no. 2 (1996): 207-23.

Kegley, Charles W. Controversies in International Relations Theory: Realism and the Neoliberal Challenge. New York: St. Martin’s Press, 1995.

Kellstedt, Paul M. and Guy D. Whitten, The Fundamentals of Political Science Research. New York: Cambridge University Press, 2009.

King, Gary, Robert O. Keohane and Sidney Verba. Designing Social Inquiry: Scientific Inference in Qualitative Research. Princeton, NJ: Princeton University Press, 1994.

Lebow, Richard Ned. Forbidden Fruit: Counterfactuals and International Relations. Princeton, NJ: Princeton University Press, 2010.

Lowenthal, Mark M. “Towards a Reasonable Standard for Analysis: How Right, How Often on Which Issues?” Intelligence and National Security 23, no. 3 (2008): 303-15.

Marrin, Stephen. Improving Intelligence Analysis: Bridging the Gap Between Scholarship and Practice. Abingdon: Routledge, 2011.

Marrin, Stephen. “The 9/11 Terrorist Attacks: A Failure of Policy Not Strategic Intelligence Analysis.” Intelligence and National Security 26, nos. 2-3 (2011): 182-202.

Martin, Christopher Phillip, Wayne Philp and William P. Hall. “Temporal Convergence for Knowledge Management.” Australasian Journal of Information Systems 15, no. 2 (2009): 133-48.

Massingham, Peter. "Linking Business Level Strategy with Activities and Knowledge Resources.” Journal of Knowledge Management 8, no. 6 (2004): 50-62. 
Mayer-Schönberger, Viktor and Kenneth Cukier. Big Data: A Revolution That Will Transform How We Live, Work and Think. London: John Murray, 2013.

Phythian, Mark. "Intelligence Theory and Theories of Intelligence: Shared World or Separate Worlds?” In Peter Gill, Stephen Marrin and Mark Phythian (eds.), Intelligence Theory: Key Questions and Debates. Abingdon: Routledge, 2009: 54-72.

Phythian, Mark. "Policing Uncertainty: Intelligence, Security and Risk.” Intelligence and National Security 27, no. 2 (2012): 187-205.

Phythian, Mark (ed.). Understanding the Intelligence Cycle. Abingdon: Routledge, 2013.

Pierce, Andrew. “The Queen asks why no one saw the credit crunch coming.” Daily Telegraph, 5 November 2008:

http://www.telegraph.co.uk/news/uknews/theroyalfamily/3386353/The-Queen-asks-why-noone-saw-the-credit-crunch-coming.html.

Warner, Michael: “Intelligence and Reflexivity: An Invitation to a Dialogue.” Intelligence and National Security 27, no. 2 (2012): 167-71.

Warner, Michael. “Theories of Intelligence: The State of Play.” In Robert Dover, Michael S. Goodman and Claudia Hillebrand (eds.). Routledge Companion to Intelligence Studies. Abingdon: Routledge, 2014: 25-32.

Wirtz, James J. “The Art of the Intelligence Autopsy.” Intelligence and National Security 29, no. 1 (2014): 1-18.

Wohlstetter, Roberta. Pearl Harbor: Warning and Decision. Stanford, CA: Stanford University Press, 1962.

Zegart, Amy B. Spying Blind: The CIA, the FBI, and the Origins of 9/11. Princeton, NJ: Princeton University Press, 2009. 